\title{
Bipolar Electrochemical Reactor Processes for Removal of Bacterial Spores: Effect of Ethanol and Potasium Iodide
}

\author{
Masuma Moghaddam Arjmand ${ }^{1,2}$, Abbas Rezaee ${ }^{1, *}$, Simin Nasseri ${ }^{3}$, Seyyed Said Eshraghi ${ }^{4}$ \\ ${ }^{1}$ Department of Environmental Health Engineering, Faculty of Medical Sciences, Tarbiat Modares \\ University, Tehran, Iran. \\ ${ }^{2}$ Department of Environmental Health Engineering, School of Public Health, Tehran University of \\ Medical Science, Tehran, Iran. \\ ${ }^{3}$ Department of Environmental Health Engineering, School of Public health, and Center for Water \\ Quality Research,Institute for Environmental Research, Tehran University of Medical \\ Scinces, Tehran,Iran \\ ${ }^{4}$ Department of Pathobiology, School of Public Health, Tehran University of Medical Sciences, \\ Tehran, Iran. \\ *E-mail: rezaee@modares.ac.ir
}

doi: $10.20964 / 2017.05 .71$

Received: 31 January 2017 / Accepted: 18 February 2017 / Published: 12 April 2017

Electrochemical techniques have a great potential in removing organic matters and resistant microorganisms from water through water treatment processes. The present study was conducted to propose a standard solution for the removal of Bacillus subtilis as a model of Cryptosporidium from drinking water using a bipolar electrochemical system. The initial number of Bacillus subtilis spores used as a Cryptosporidium surrogate for water quality assessment was $10^{2}-10^{4}$ spores $/ \mathrm{mL}$. The electrochemical reaction took 15 to 60 minutes to complete and occurred in the presence of $0.4 \mathrm{M}$ of ethanol and $4 \mathrm{mg} / \mathrm{L}$ of $\mathrm{KI}$ and at a current density of 3-5 $\mathrm{mA} / \mathrm{cm}^{2}$, at ambient temperature and with normal $\mathrm{pH}$ water. The findings suggest that, under optimal conditions of Bacillus subtilis spore removal, the synergistic effects of bipolar electrochemical reactions in the presence of KI and ethanol lead to a $32 \%$ reduction in energy consumption compared to when only a single electrochemical process is used.

Keywords: Bipolar electrochemical reaction, ethanol, supporting electrolyte, Bacillus subtilis spores, water disinfection

\section{$\underline{\text { FULL TEXT }}$}


(C) 2017 The Authors. Published by ESG (www.electrochemsci.org). This article is an open access article distributed under the terms and conditions of the Creative Commons Attribution license (http://creativecommons.org/licenses/by/4.0/). 